\title{
Primary Hydatid Cyst Posterior Triangle of Neck in a Child of 10 Years of Age
}

\author{
Hamid R', Shera A H², Bhat N A ${ }^{3}$, Khurshid Sheikh ${ }^{4}$, Baba A A ${ }^{5}$, Rasheed A ${ }^{6}$, Akhter A $^{7}$ \\ ${ }^{1}$ Dr. Raashid Hamid, MBBS, MS, Senior Resident, ${ }^{2}$ Dr. Altaf Hussain Shera, MBBS, MS, MCh, Professor and Head of \\ Department, ${ }^{3}$ Dr. Nisar Ahmad Bhat, MBBS, MS, Mch, Assistant Professor, ${ }^{4}$ Dr. Sheikh Khursheed, MBBS, MS, Professor, ${ }^{5}$ Dr. \\ Aejaz A Baba, MBBS, MS, MCh, Assistant Professor, ${ }^{6}$ Dr. Abdul Rasheed, MBBS, MS, MCh. Assstant Professor, ${ }^{7}$ Dr. Afrozah \\ Akhter, MBBS, PG Resident. All from the department of Paediatric Surgery, SKIMS, Srinagar, Jammu and Kashmir, India.
}

Address for correspondence: Dr. Raashid Hamid, E-mail: drraashidhamid@gmail.com

\begin{abstract}
A case of hydatid cyst involving posterior triangle of neck in a 10 year old male child is reported. Diagnosis was confirmed by MRI. Surgical excision of the cyst was done. Hydatid cyst in posterior triangle should be considered one of the possibilities in evaluating a cystic swelling in this region.
\end{abstract}

Key words: Hydatid, Posterior triangle, Neck

\section{Introduction}

$\mathrm{H}^{\mathrm{y}}$ ydatid disease is caused by Echinococcus granulosus and Echinococcus multilocularis. Although it most commonly involves liver and lungs, any organ or tissue can be primary sites of hydatid disease ${ }^{1,2}$. Hydatid cysts are rare in head and neck region ${ }^{3}$. We report an unusual case of hydatid cyst in right posterior triangle of neck in an eleven year old child, thus remind the clinician that in a cystic benign lesion of posterior triangle of neck, hydatid cyst may be kept one of the differential diagnosis.

\section{The Case}

An eleven year old boy presented to us as a case of swelling right side of neck in the posterior triangle. The boy was referred from Sub-District Hospital to our tertiary care hospital for management. Swelling was painless and parents of the child had noticed it two months back. There was no history of any other swelling in the body, fever, weight loss or decreased appetite.

On examination, swelling was cystic in consistency, located in posterior triangle of neck. Size of the swelling was about $3 \times 3 \mathrm{~cm}$. It was non-tender. There were no signs of inflammation. USG of the neck revealed two cystic swellings in the deep subcutaneous tissue of neck between clavicle and trapezius muscle. MRI of neck revealed two cystic swellings measuring $4 \times 3 \mathrm{~cm}$ and $3 \times 1 \mathrm{~cm}$. [Figure 1], [Figure 2], [Figure 3]. An impression of hydatid cyst was made. ELISA for hydatid was positive. USG and CT of chest and abdomen were normal.

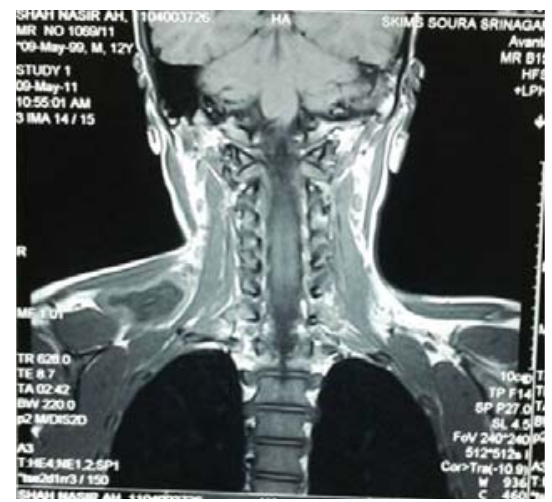

Fig 1: MRI T1-Weighted-Coronal view of neck showing a cystic lesion on right side of neck between trapezius muscle posteriorly and clavical anteriorly.

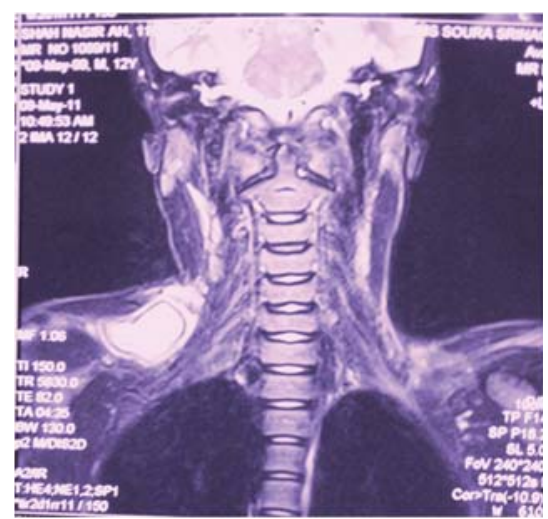

Fig 2: MRI T2-Weighted-Coronal view of neck showing a cystic lesion in right side between trapezius muscle posteriorly and clavical anteriorly. 


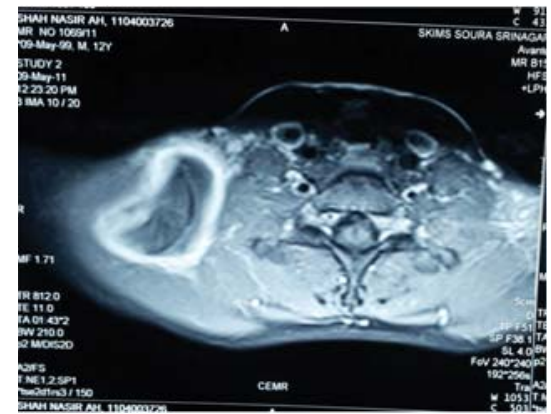

Fig 3: MRI T1-Weighted-Cross section view of neck showing a cystic lesion in right side of neck.

Patient was taken for excision of the cyst. Intraoperative findings confirmed the laminated hydatid membranes and both the cysts were excised in total. Analysis of the fluid and cyst confirmed the hydatid disease. Patient is doing well without any complaint till now.

\section{Discussion}

Hydatid disease is a parasitic infection distributed worldwide. It is more common in sheep and cattle rearing regions of Australia and South America. This infection is common in Kashmir (India) as ours is a rural population. Hydatid cyst can affect any part of the body but most common are liver (75\%), lung (15\%) and multi-organ involvement has been reported in 20-30\% of hydatid disease cases 4 . But the involvement of head and neck is very uncommon even in endemic areas ${ }^{5}$. It may come into notice either after an USG or clinical examination as in our patient. Posterior triangle neck is an uncommon site for hydatid disease and only one case has been reported so far in an adult patient. Ours is the first case of hydatid cyst in posterior triangle in a 10 year old child. Literature shows the disease is more common in people from rural background who are associated with domestic farming duties. In endemic areas, the hydatid cyst of head and neck accounts for only $1 \%$ of hydatid disease. The lesions are slow growing and the manifestations depend upon location, size and pressure caused by the cyst ${ }^{5,6}$. Preoperatively diagnosing a hydatid cyst at an unusual site may be missed, unless suspected or demarcated radiologically ${ }^{6,7}$. USG has an important role in detecting a hydatid cystic lesion. Multiple hypoechogenic images noted within the cystic lesion of hydatid. CT is a complementary study of hydatid cysts especially in liver and lung. It describes size, exact site, type or any calcification present in the cyst. MRI has very important role in detecting the cystic lesion like hydatid in soft tissue areas like post triangle of neck as in our case ${ }^{5} . T_{1}$ weighted images show low intensity signal and $T_{2}$ weighted images show high intensity signal. MRI provides an assessment of extension into soft tissue and the calcification of the cyst if present. A serological test for diagnosis of hydatid disease has low sensitivity and specificity and has only limited use especially in case of extrahepatic hydatid disease ${ }^{2}$.

Surgical removal of hydatid cyst remains the most effective treatment as was done in our case. Aim of surgery should be total removal of the cyst, avoiding the spillage. Outcome of medical treatment is required to be determined. PAIR technique is one of the procedures used for uncomplicated liver hydatid cysts but the PAIR method has not been applied to a cyst in posterior triangle of neck which is very rare.

\section{Conclusion}

Hydatid disease should be considered in differential diagnosis of cystic lesion of posterior triangle neck in children. Although it is rare in children, the diagnosis if in doubt should be settled by CT and MRI. Surgeon must be aware of the condition in order to offer accurate diagnosis and definitive treatment.

\section{References}

1. Arslan H, Sakarya ME, Bozkurt M, et al. Free hydatid cyst only covered with germinative membrane disrupted from fibrotic capsule in the peritoneal cavity: a case report. Acta Chir Belg 1998; 98(2): 85-6.

2. Mandell GL, Douglas RG, Bennett JE. Mandell GL, Douglas RG, Bennetts Principles an practice of Infectious Diseases. 5th ed. Philadelphia: Churchill Livingstone. 2000; 5: 2962.3.

3. Onerci M, Turan E, Ruacan S. Submandibular hydatid cyst. J Cranio-Max-Fac Surg 1991;19:359-361.

4. Rauhofer U, Prager G, Hormann M, Auer H, Kaserer $K$, Niederle $B$. Cystic echinococcosis of the thyroid gland in children and adults. Thyroid 2003;13: 497502.

5. Michail OP, Georgiou C, Michail PO, Felekouras E, Karavokyros I, Marinos G et al. Disappearance of recurrent intra-abdominal extrahepatic hydatid cyst following oral albendazole administration. West Indian Med J 2007; 56(4):16-21.

6. Akal M, Kera M. Primary hydatid cyst of the posterior cervical triangle. J Laryngol Otol 2002;1 16:153-155.

7. Akyildiz, A. N., Ozbilen, M. S., Goksu, N. (1991) Hydatid cyst of the pterygopalatine fossa. Journal of Oral and Maxillofacial Surgery 1991;49: 87-88.

\section{How to cite this article?}

Hamid R, Shera A H, Bhat N A, Khurshid Sheikh, Baba A A, Rasheed A, Akhter A. Primary Hydatid Cyst Posterior Triangle of Neck in a Child of 10 Years of Age. J Nepal Paediatr Soc 2012;32(3):261-262. 